\title{
Strengthening the research capacity of Planned Parenthood Association of Ghana
}

Robert A. Miller

Population Council

Follow this and additional works at: https://knowledgecommons.popcouncil.org/departments_sbsr-rh

Part of the Demography, Population, and Ecology Commons, Health Services Research Commons, and the International Public Health Commons How does access to this work benefit you? Let us know!

\section{Recommended Citation}

Miller, Robert A. 1998. "Strengthening the research capacity of Planned Parenthood Association of Ghana." New York: Population Council. 
Final Report

\section{Strengthening the Research Capacity of the Planned Parenthood Association of Ghana (PPAG)}

May 1996 - September 1998

Robert A. Miller

Africa OR/TA Project II

December 1998 


\section{Background}

The Planned Parenthood Association of Ghana (PPAG) is one of the most active nongovernmental organizations delivering reproductive health services in Ghana. PPAG has focused particular attention on youth issues and services since 1972. PPAG has received USAID funding establishing Youth Centers, and conducting baseline assessments for eventual evaluations of youth programs.

With a history of active involvement with PPAG, USAID suggested to the Population Council's Africa OR/TA Project II staff that PPAG might benefit from technical assistance from Project staff. An initial visit conducted by Robert Miller in May 1996 indicated that there were considerable opportunities available to strengthen PPAG's Research and Evaluation Division. PPAG had been operating predominantly in the mode of a service delivery agency. Its Research and Evaluation Division was used mostly for program evaluation. The consultant discussed with the Executive Director and other staff the possibility of adjusting the goals of the organization to pioneering new services on an experimental basis, including he use of simple quasi-experimental designs to answer important program design questions prior to expanding them. Also discussed was the idea of conducting studies to find models that may be appropriate for other institutions to carry out, rather than trying to conduct service delivery programs in ever-expanding areas.

A large and well-funded IPPF program to promote sexual health among youth of Volta Region offered a particularly good opportunity to begin OR work. Earlier, the program was envisioned as a demonstration program of five years duration. It was to include a before-survey, a mid-point survey, and final assessment survey to evaluate a very intensive educational program. Further discussions suggested that this demonstration educational program was unlikely to be duplicated anywhere, both because of its high cost, and because the design of the evaluation did not include a comparison area. As a result, even if the surveys documented change in the program, it would be unclear how much change resulted form the program activities and how much resulted from other, non-program factors.

The staff of PPAG demonstrated considerable flexibility with their plans, and interest in the conduct of an operations research approach to some of the particular problems and opportunities available. Further, it was PPAG's assessment that IPPF would appreciate an OR approach more than a demonstration approach to the sexual health issue for youth. Therefore PPAG was interested in a collaborative relationship with the Population Council's Africa OR/TA Project II. The USAID Mission also supported this relationship. Therefore, Africa OR/TA Project II and PPAG developed a project to strengthen PPAG's research capacity 


\section{Objectives}

\section{Ultimate Objective}

To enhance and expand PPAG's research capacities for conducting OR studies.

Immediate Objectives

1. Assist staff of the Research and Evaluation Division to strengthen their skills in the OR design and data analysis through short-term training and technical consultation.

2. Upgrade the computer hardware and software available to the Research and Evaluation Division.

3. Assist staff to conduct the steps necessary to fully implement an OR Project, including: developing a research design, creating and pre-testing a baseline instrument, analyzing baseline data, writing reports, supervising, managing, and documenting the interventions; conducting a final assessment, and writing a final report. In addition, technical assistance was to cover developing appropriate monitoring and evaluation plans for selected on-going USAID-funded projects.

\section{Activities and Accomplishments}

Strengthening Staff skills: Two PPAG staff members were sent for short-term courses at Exeter University, Institute for Population Studies, in the United Kingdom. Angela Bannerman, Research Officer, attended a six-week course on Family Planning Operations Research Design, and Kofi Glover, Research and Evaluation Manager, attended a six-week course in Collection and Analysis of FP and RH Data. In addition, several consultants provided a number of informal training programs in-country as part of their consultation activities. Subjects that received emphasis during consultations included: OR research design and implementation issues; use of the SPSS program to conduct data analysis; protecting the computer system from viruses; issues in program implementation, MIS; presentation skills; and others.

Upgrading Computer Hardware and Software: In 1996, Population Council supplied a Compaq Desk Pro $75 \mathrm{MHz}$ Pentium computer, equipped with $16 \mathrm{MB}$ of RAM, CD drive, and an HP LaserJet 5 printer. Software supplied included: Windows 95; Microsoft Office Suite; SPSS; McAfee Virus Protection; and the PopLine CD ROM. This computer system made a substantial improvement in PPAG's analytic and computer capability. Dr. Placide Tapsoba provided consultation on the setup and installation of programs. He discovered that all of PPAG computers and disks were infected with the ANewbug” virus. Kofi Glover, suspecting viral 
contamination of the entire office environment, had kept colleagues from using disks from other machines on the new research computer, which was not contaminated. Dr. Tapsoba installed the anti-viral software on the new computer, instructed PPAG staff in its use. He recommended that: all machines and disks in the PPAG be checked for viruses and cleaned; virus protection software be installed on all PPAG computers; and staff be trained in its use. Population Council staff also delivered updated virus protection software.

Assisting Staff to Conduct an OR Experiment: This activity was the main focus of the six technical assistance visits provided by Robert Miller, Annabel Erulkar, and Heidi Jones. This activity resulted in the following collaborative products and accomplishments, reports of which have been submitted to USAID.

\section{1. "An Operations Research Approach to the Development of a Cost-Effective Strategy for Strengthening Reproductive Health Among Ghanaian Youth" (A draft proposal submitted with Robert Miller's Trip Report, May 13-26, 1996).}

The USAID Mission had funded several Youth Centers in Ghana. However, research in a number of countries was suggesting that the youth center approach may be less productive and efficient than the peer promoter approach. PPAG decided to design an OR study to test the peer promoter approach alone, against a program of peer promoters in combination with youth centers. Both programs were to be implemented within the overall context of PPAG's participatory approach to community education. Two experimental and one comparison groups were to be used in the rural areas of Volta Region.

The dependent variables included exposure to communication and service, and changes in broad knowledge, attitudes, and practices surrounding a number of issues in sexual health. These issues included: safer sexual practices, such as condom use and non-penetrative sexual activity; strengthened self-image; improved gender relations; reductions in drug and alcohol use, and others.

Assessment of the effectiveness and cost- effectiveness of the two approaches are based on service records, and on changes measured by a before and after survey of the youth population. 


\section{The development of a comprehensive instrument for measuring variables of interest in before and after surveys.}

The instrument was developed collaboratively between Population Council and PPAG staff after a review of several instruments used by other researchers in Kenya, Nigeria, and Zimbabwe. Because USAID had recently funded three new youth centers in regional towns, it was decided to conduct a substantial pretest of the instrument. Two hundred-fifty youth in each of these towns were interviewed, after being selected to represent three different groups: in-school youth; out of school youth organized in apprenticeship programs, and out-of-school "street youth." This pretest was used to collect relevant information for planning the Youth Center programs, and to establish a baseline for evaluating these programs.

\section{The development of an "Interviewers' Training Manual" for the conduct of the Volta} Region Baseline Survey and the provision of assistance on the training of interviewers (Submitted with the Trip Report of Annabel Erulkar, May 18 - July 1, 1997).

Considerable assistance was provided by Annabel Erulkar, Population Council staff member based in Nairobi, in both sharpening the draft survey instrument and training field research staff in its use. The interview schedule was revised to make it shorter, eliminate redundancies, and provide complete instruction in an easy and consistent manner. Following a lengthy review, both the boy and girl versions of the instrument were produced and revised. The result was parallel instruments, with extra questions for girls on pregnancy and different questions for boys and girls on wet dreams and menstruation. Both instruments were pre-tested and modified prior to fielding on a large scale.

Erulkar facilitated the training of the 20 interviewers during the first week of their training. These interviewers were young and inexperienced in any kind of work, and represented a considerable challenge. Participants reviewed and practiced the interview schedule, section by section. Several role-plays of interviews were conducted and critiqued. The training also included training on family planning and reproductive health. In the second week of training, PPAG created additional practice sessions on using the instruments in the local language, and practice using the instruments in the field. 


\section{Report on Town Youth: “Adolescents' Experience with Sexuality in Three Ghanaian Towns" is the most recent draft (attached). An earlier draft was titled: "Adapting Reproductive Health Strategies to Adolescent and Youth Needs: Findings from Three Ghanaian Towns."}

These reports indicate that youth are most concerned about economic issues and tend to accept violence toward women. Drug abuse does not appear to be a substantial problem. About half of never married males and females have had sexual intercourse, and a third were sexually active in the month preceding the interview. Respondents are generally familiar with methods of preventing pregnancies and sexually transmitted infections, but only about half used modern contraceptives the last time they had sex and half have ever used a condom. Respondents by and large lack basic information on such important sexual health facts as correct condom use and the timing of a woman's fertile period, which may put them at greater risk of unwanted pregnancies and STIs.

This paper also included differences between the three populations examined. In-school youth are the least sexually active and have the most liberal reproductive health attitudes. Apprenticed youth have the highest levels of sexual activity; they generally have more accurate information on reproductive health issues but are less likely to use condoms. Unaffiliated youth hold the most conservative views on sexual health and are the most tolerant of violence towards women. They are less sexually active than apprenticed youth but those who are having sex tend to have more partners and use condoms less.

\section{Dissemination of the Town Youth Report.}

Many agencies and individuals indicated substantial interest in the results of the town data, and the findings were disseminated widely, in some cases along with findings from the Volta Region before survey data. An active dissemination program included several presentations based on data, including: (1) at an initial meeting of FOCUS; (2) at the APHA meeting in Indianapolis, November 1997 where Kofi Glover presented "Reproductive Health knowledge and Practices Among Ghanaian Youth: A Rural-Urban Comparison"; and (3) at USAID, November 1997. At the USAID presentation, participants in the discussion represented CEDPA, JHPIEGO, Population Action Aid, Horizons, PCS, Inopal, Focus, and the Population Reference Bureau, in addition to USAID. Findings were also included in the End of Project Conference for Africa OR/TA Project II in Nairobi, and a planning meeting on youth organized by the Frontiers Project as a part of planning for the Project's Global Agenda.

The earlier draft was submitted to an international journal. While appreciating the usefulness of the findings, reviewers expressed concern that the analysis may not have adequately controlled for age, and that it discussed so many different issues that the "story line" of the paper was not entirely clear. The new draft, produced with the additional assistance of Brian Pence, was 
designed to eliminate these criticisms and will be submitted to International Family Planning Perspectives as soon as PPAG comments and suggestions are integrated.

\section{Analysis and Dissemination of the Rural Data}

PPAG conducted an initial analysis of the rural data. Jones reworked PPAG's analysis of the baseline rural data from the Volta Region which provided an opportunity for Jones to use an applied approach to teaching SPSS programming. Erulkar worked further on this analysis with PPAG staff, with has planned to produce additional papers collaboratively.

Results from the rural baseline study were presented at APHA in Washington, DC in 1998. This extensive work on the baseline analysis will facilitate the analysis of the after survey data.

\section{PPAG Staff Development During Dissemination}

In preparation for the presentation of the Town Data, Population Council staff worked with Kofi Glover in New York to strengthen his data analysis and presentation skills. In addition, Glover had several other useful activities during this trip. He visited The Family Planning Association of New York City - Margaret Sanger International, where he made a presentation on PPAG's youth programs and research. He also visited a PPNYC clinic to review service provision, and had a night tour of an outreach program for young sex workers in NY City.

\section{Further development of PPAG's MIS forms to monitor the implementation of the OR} study, and further analysis the Volta Region Baseline data (Submitted in Heidi Jones' Trip Report, March 22 - April 5, 1998).

Annabel Erulkar had previously assisted PPAG staff to develop a series of forms for monitoring the implementation of the OR study. The MIS forms were finalized with the assistance of Jones, making sure that the experimental cells for the OR design were well-differentiated on the forms, and that the subcategory within the out-of-school groups were also captured, to be consistent with data analysis plan. Jones also visited the OR sites, reviewed the implementation of the study, and made recommendations for strengthening field implementation. The main issues dealt with were: (1) whether the interventions were being implemented at a sufficiently intense level to create a possible measurable difference in the experimental areas; and (2) whether the supervision of both the OR study, and the field implementation of interventions was sufficient. Several recommendations were made for strengthening these elements, and forms were developed to improve the tracking of the interventions, contacts, and services provided. 


\section{9. "Youth Centres in Ghana: Assessment of the Planned Parenthood Association of Ghana Programme" (Submitted October, 1998)}

At the request of PPAG and the USAID Mission, Annabel Erulkar assisted in conducting a review of PPAG's youth center programs. This analysis included the use of seven data sources, including interviews with all professional staff and volunteers, exit interviews with clients, a retrospective analysis of clinic records, attendance of clients, retrospective analysis of IEC activities, review of the facilities and equipment; and cost data from annual reports. Numerous recommendations for strengthening the youth center programs resulted from this review. These included making changes in privacy, signboards, hours of operation, availability of trained and motivated staff, record keeping, community involvement, increase training for volunteers, increased training on gender issues, outreach, broader RH information, and facilities.

\section{Summary of Accomplishments and Lessons}

Institutionalizing an OR capacity is a long-term activity, and is not easy to achieve. Fortunately, the combination of varied technical assistance and training activities, along with the actual experience of implementing an OR project in Volta Region, appears to have strengthened PPAG's OR capacity significantly. Substantial data have been collected on a wide range of issues from approximately 750 town youth, and 2200 rural youth. To date, the analysis of the town and rural data has been widely disseminated and has proven to be of substantial interest to a variety of agencies dealing with youth issues.

A major product of this activity will be a final report on the Volta Region OR experiment with different approaches to youth - PPAG's first OR activity. It will not be possible to assess the success of this activity fully until the final analysis of PPAG's initial OR project takes place, and PPAG develops plans for other OR activities in the future. Nevertheless, at this "midpoint," there are some tentative lessons that may be considered:

1. The combination of periodic TA, by a variety of consultants with different skills, training of staff in short term courses, improvements in computer equipment, and remote TA provided periodically from New York and Nairobi, appears overall to have been a suitable approach for PPAG.

2. An important feature of the TA was customizing the assistance to the steps necessary to implement an OR experiment: project design; development of data collection instruments; training of field staff; pre-testing instruments; analyzing data; developing MIS and monitoring program implementation; final data collection; analysis of results; dissemination of study results; and utilization of the results. 
3. Not all of these activities have been completed, and considering the investment in this institutionalization process, it should be seen through to conclusion.

4. A possible shortfall in this activity was the amount of attention devoted to the supervision of field implementation. Factors associated with this include the selection of an OR field site at some distance from PPAG's central office. This had the effect of reducing the amount of hands-on supervision of the field research and implementation team by the central office staff, who carry many additional responsibilities. Additionally, the TA team may not have provided sufficient assistance in this crucial area. What is known now is that field implementation is an area of potential weakness. However, it is unclear at this point whether it represents a serious problem, or whether the steps taken by PPAG to solve this problem have been effective.

\section{Recommendations for Next Steps and Future Technical Assistance}

1. The technical assistance on OR provided under Africa OR/TA Project II should be continued.

2. Specific areas for assistance should include:

Reviewing the OR experience to date and determining the amount and type of assistance that may be required/desired by PPAG.

Reviewing the field implementation of the study and determining the state of the MIS on interventions, and client services. This will provide an initial indicator of the number and types of contacts in each program, and the overall intensity of the program effort achieved.

Assistance with implementation of the After survey as required, and on the analysis of the amount of change in dependent variables achieved between the before and after surveys in the two experimental and comparison areas.

Assistance with the write-up and dissemination of the Volta Region experimental findings.

Developing future plans for other research and evaluation activities, and technical assistance as may be required/desired, such as an assessment of PPAG's CBD program. 